\title{
IdeAs
}

Idées d'Amériques

$11 \mid 2018$

Modernités dans les Amériques : des avant-gardes à aujourd'hui

\section{Lukáš Perutka, Checoslovaquia, Guatemala y México en el período de la Revolución guatemalteca}

Prague, Université Charles, Ed. Karolinum, 2014, Ibero-Americana

Pragensia - Suplementum (32), 166 pages

Alvar De la Llosa

\section{CpenEdition}

\section{Journals}

Édition électronique

URL : https://journals.openedition.org/ideas/2698

DOI : $10.4000 /$ ideas. 2698

ISSN : $1950-5701$

Éditeur

Institut des Amériques

Référence électronique

Alvar De la Llosa, «Lukáš Perutka, Checoslovaquia, Guatemala y México en el período de la Revolución guatemalteca », IdeAs [En ligne], 11 | 2018, mis en ligne le 18 juin 2018, consulté le 19 octobre 2022 URL : http://journals.openedition.org/ideas/2698 ; DOI : https://doi.org/10.4000/ideas.2698

Ce document a été généré automatiquement le 19 octobre 2022.

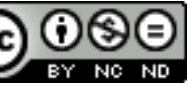

Creative Commons - Attribution - Pas d'Utilisation Commerciale - Pas de Modification 4.0 International - CC BY-NC-ND 4.0

https://creativecommons.org/licenses/by-nc-nd/4.0/ 


\section{Lukáš Perutka, Checoslovaquia, Guatemala y México en el período de la Revolución guatemalteca}

Prague, Université Charles, Ed. Karolinum, 2014, Ibero-Americana

Pragensia - Suplementum (32), 166 pages

\section{Alvar De la Llosa}

\section{RÉFÉRENCE}

Lukáš Perutka, Checoslovaquia, Guatemala y México en el período de la Revolución guatemalteca, Prague, Université Charles, Ed. Karolinum, 2014, Ibero-Americana Pragensia - Suplementum (32), 166 pages

1 Après avoir méthodiquement détaillé les relations existantes entre 1922-1939 marquées par l'établissement de relations consulaires, d'achats de café et de ventes d'armes - Lukáš Perutka apporte un regard neuf sur les relations entre le Guatemala et la Tchécoslovaquie. Il les intègre dans le vaste cadre des besoins industriels de l'Amérique latine au sortir de la Seconde Guerre mondiale, et de la volonté des élites les plus libérales d'élargir le volume des échanges commerciaux par le biais d'une complémentarité économique d'échanges entre des produits tropicaux et des machines destinées au développement agricole et à la construction d'infrastructures routières. Or, Prague sursoit à répondre aux demandes guatémaltèques - à partir de 1954 seulement - car le gouvernement Arbenz (1951-1954) est analysé comme faible dans un espace dominé par les États-Unis, ce qui provoque une réponse tardive à une demande de matériel industriel lourd.

2 À travers huit chapitres, Perutka offre un éclairage nouveau sur le gouvernement Arbenz et le besoin guatémaltèque de se procurer, auprès de la Tchécoslovaquie, des armes qui, en partie, avaient été achetées avant 1939. Le refus de l'OTAN conduisit le pays centre-américain à revenir vers Prague après que Washington a imposé un 
embargo sur les armes, y compris... les cartouches de chasse... À travers les documents tchèques, l'envers du décor et le troisième acteur apparaissent. Perutka montre comment cette affaire des armes tchèques fut instrumentalisée par les États-Unis qui avaient déjà entamé leur campagne de dénigrement contre le gouvernement d'Arbenz qui cherchait à moderniser et développer son pays en sortant des modèles imposés, sans accepter pour autant de devenir un pion de Moscou. Cette " affaire " permettrait de justifier le coup d'État de 1954, et faire oublier le rôle de la CIA à travers la puissante United Fruit $\mathrm{C}^{\circ}$. Les archives étudiées démontent aussi des affirmations orales rapportées par la bibliographie, notamment celle de José Manuel Fortuny qui affirmait que le président guatémaltèque lui avait dit que les armes serviraient à armer la population; or les archives tchèques prouvent que le matériel était bien destiné à l'Armée. Autre révélation de manipulations propres à la Guerre froide, les armes n'étaient pas, comme le prétendit la presse étasunienne sur la foi de la CIA, des armes neuves produites par Skoda, mais des armes de piètre qualité puisque prises à la Wehrmacht en 1945, dix ans auparavant!

3 Au-delà de l'incongruité de faire croire que le Guatemala avait les moyens de payer des armes de haute technicité, il s'agissait pour Washington de donner à penser que le petit pays centre-américain représentait un danger pour la sécurité continentale. Perutka dévoile aussi le montant de la transaction, 10 millions de dollars américains selon les États-Unis, en réalité 2 à 2,5 millions, à une époque où Guatemala n'avait d'ailleurs pas les moyens financiers nécessaires à l'ouverture d'une légation à Prague...

4 Remercions donc Perutka d'éclairer d'un jour nouveau une affaire oubliée sur laquelle on pensait tout savoir depuis la récente ouverture des archives étasuniennes déclassées. Il nous révèle non seulement un modèle de politique étatique d'un accès possible aux archives, mais une large ouverture sur un aspect ignoré à l'Ouest des relations entre l'Amérique latine et les pays de l'Est européen, favorisant de la sorte la connaissance d'une bibliographie dont l'accès est généralement freiné par la méconnaissance de la langue tchèque, mais qui enrichit énormément une vision globale des relations entre des puissances secondaires

\section{AUTEURS}

\section{ALVAR DE LA LLOSA}

Professeur en civilisation latino-américaine, Université Lyon 2 